EXTENDED REPORT

\title{
Suprascapular nerve block in chronic shoulder pain: are the radiologists better?
}

\author{
E M Shanahan, M D Smith, M Wetherall, C W Lott, J Slavotinek, O FitzGerald, M J Ahern
}

Ann Rheum Dis 2004;63:1035-1040. doi: 10.1136/ard.2003.015909

See end of article for authors' affiliations

.....................

Correspondence to: Dr E M Shanahan, Rheumatology Research Unit, Repatriation General Hospital, Daw Park, South Australia, Australia 5041; michael.shanahan@rgh. sa.gov.au

Accepted

19 November 2003

\begin{abstract}
Background: Suprascapular nerve block is a safe and effective treatment for chronic shoulder pain in arthritis, which can be performed either by direct imaging (CT guided) or in the clinic using anatomical landmarks to determine needle placement.

Objective: To compare a CT guided versus an anatomical landmark approach in a randomised, single blind trial examining the efficacy of suprascapular nerve block for shoulder pain in patients with degenerative joint/rotator cuff disease.

Methods: 67 patients with chronic shoulder pain from degenerative disease participated in the trial. 77 shoulders were randomised. The group randomised to receive the block through the anatomical landmark approach received a single suprascapular nerve block. Those in the CT guided group received an injection of methylprednisolone acetate and a smaller volume of bupivacaine around the suprascapular nerve. The patients were followed up for 12 weeks by a "blinded" observer and reviewed at weeks 1, 4, and 12 after the injection.

Results: Significant improvements were seen in all pain scores and disability in the shoulders receiving both types of nerve block, with no significant differences in the improvement in pain and disability between the two approaches at any time. Improvements in pain and disability scores were clinically and statistically significant. No significant adverse effects occurred in either group. Patient satisfaction scores for pain relief using either approach were high.

Conclusion: The CT guided control and landmark approaches to performing suprascapular nerve blocks result in similar significant and prolonged pain and disability reductions; both approaches are safe.
\end{abstract}

$\mathrm{S}$ uprascapular nerve block has been shown to be a safe and effective treatment for chronic shoulder pain from arthritis. ${ }^{1}$ When performed in the clinic using anatomical landmarks to site the injection it reduces pain and disability when compared with placebo. Recently, an alternative method of performing this procedure has been reported using computed tomographic (CT) guidance to locate the needle next to the suprascapular nerve at the suprascapular notch. ${ }^{2}$ The recently reported series by Schneider-Kolsky et al showed encouraging results with this approach, although there was no control group in the study. It appeared appropriate to compare directly the landmark approach with the CT guided approach for the following reasons:

- Suprascapular nerve block is a useful adjunct treatment for patients with chronic shoulder pain and we wished to determine the better method for this treatment

- Few clinical trials directly compare radiologically guided interventions with indirect methods using patient based outcomes and we wished to undertake such a comparison.

For these reasons we designed and performed a randomised trial directly comparing the two approaches using pain, disability, and patient satisfaction scales as our major end points. We did not aim to undertake a trial of equivalence but wanted to see if one approach was clinically better than the other. According to Jones et al the aim of an equivalence trial is to show the therapeutic equivalence of two treatments, ${ }^{3}$ however when an active comparator is used the expectation may be that the new treatment will be better than the standard. This situation is similar to using a placebo control. We aimed at performing a comparative trial to determine if the "new" treatment (CT guided suprascapular nerve block) would be better than the "standard" (landmark approach). We felt this was an appropriate methodological approach for two reasons. Firstly, the clinical efficacy of the landmark method of the suprascapular nerve block versus placebo has already been established. Secondly, we felt that the radiological approach would need to be shown to produce a better outcome if it were to be employed because of the greater costs of this approach and the radiation exposure. This approach would also have methodological advantages in the sample size and analysis ${ }^{3}$ compared with a trial of equivalence.

\section{METHODS}

A single blind randomised trial was designed. Given the differences in the two approaches it was considered impossible to adequately blind the patients as to the type of intervention performed. However, after informed consent and the performance of the suprascapular nerve block the patients were asked not to disclose the nature of the intervention to the assessor for the duration of the trial. It was considered inappropriate to have a placebo arm in this study because of the proven efficacy of the intervention. ${ }^{14-6}$

The anatomical landmark approach involved an $11 \mathrm{ml}$ injection into the suprascapular fossa with $10 \mathrm{ml}$ of $0.5 \%$ bupivacaine and $40 \mathrm{mg}$ of methylprednisolone after a subcutaneous injection of $1 \%$ lidocaine for local analgesia. The method of the injection was that described by Dangoisse et $a .^{7}$ Anatomical landmarks were used to identify the injection site. Patients were seated and a line drawn along the length of the spine of the scapula. This was bisected with a vertical line drawn from the angle of the scapula dividing

Abbreviations: $\mathrm{CT}$, computed tomography; SPADI, shoulder pain and disability index; VAS, visual analogue scale 
Table 1 Demographic data-landmark versus CT guided injection

\begin{tabular}{lll}
\hline & $\begin{array}{l}\text { Landmark } \\
\text { approach } \\
\text { (n=40) }\end{array}$ & $\begin{array}{l}\text { CT guided } \\
\text { approach } \\
\text { ( } \mathbf{n}=37)\end{array}$ \\
\hline $\begin{array}{l}\text { Age (years), mean (SD) } \\
\text { Sex (M:F) }\end{array}$ & $\begin{array}{l}74.5(15.2) \\
21: 19\end{array}$ & $\begin{array}{l}76.0(9.0) \\
17: 20\end{array}$ \\
Shoulder & Left 19; right 21 & Left 14; right 23 \\
Clinical diagnosis & & \\
OA & 37 & 32 \\
RA & 3 & 5 \\
Duration of symptoms & $64.4(32.8)$ & $62.6(29.7)$ \\
(months), mean (SD) & & \\
\hline
\end{tabular}

$\mathrm{OA}$, degenerative disease (primary osteoarthritis and/or rotator cuff degeneration); RA, primary diagnosis of rheumatoid arthritis.

the scapula into quadrants. After skin preparation and local anaesthesia, a $21 \mathrm{G} \times 38 \mathrm{~mm}$ needle was introduced through the skin $2.5 \mathrm{~cm}$ along the line of the spine in the upper outer quadrant. The needle was directed over the spine in the plane of the scapula and advanced to the hub of the needle or until contact was made with the floor of the suprascapular fossa. After attempted aspiration, the agent was slowly injected to fill the fascial contents of this fossa to produce an indirect suprascapular nerve block. At this point the suprascapular nerve gives off branches to supply the glenohumeral joint, the acromioclavicular joint, and the supaspinatus muscle.

The CT guided approach was performed using a GE ZXi scanner (Milwaukee, Wisconsin, USA). After consent and explanation of the procedure the patient was placed prone with the arm on the side to be injected placed above the head. After acquisition of a scout image, preliminary $3 \mathrm{~mm}$ slices were obtained in order to localise the suprascapular notch. In some instances the preliminary images were omitted and the suprascapular notch was localised by CT fluoroscopy.

After sterile preparation and skin local anaesthesia a $38 \mathrm{~mm}, 18 \mathrm{G}$ guide was placed under CT fluoroscopic guidance $(5 \mathrm{~mm}$ thick slices, $120 \mathrm{kVp}, 50 \mathrm{~mA}, 0.7 \mathrm{~s}$ rotation time). A coaxial $9 \mathrm{~cm}, 22 \mathrm{G}$ spinal needle was then used to
Table 2 Clinical and imaging findings of shoulderslandmark versus $\mathrm{CT}$ guided injection

\begin{tabular}{lcc}
\hline & $\begin{array}{l}\text { Landmark } \\
\text { injection group } \\
(\mathbf{n}=\mathbf{4 0 )}\end{array}$ & $\begin{array}{l}\text { CT guided } \\
\text { injection } \\
(\mathbf{n}=\mathbf{3 7})\end{array}$ \\
\hline$x$ Ray findings & 2 & 8 \\
Normal & 10 & 7 \\
GH changes only & 9 & 6 \\
AC changes only & 9 & 12 \\
GH and AC changes & 7 & 0 \\
Greater tuberosity changes only & 1 & 2 \\
Subacromial changes only & 2 & 2 \\
Not performed & & \\
Ultrasound findings & 3 & 3 \\
Normal & 10 & 6 \\
Partial tear supraspinatus tendon & 18 & 18 \\
Full tear supraspinatus tendon & 2 & 0 \\
Biceps rupture only & 1 & 4 \\
Other rotator cuff tears & 2 & 0 \\
Tendonitis only & 2 & 6 \\
Not performed & & \\
Clinical findings & 11 & 16 \\
Global painful movement & 11 & 9 \\
Painful arc & 2 & 6 \\
Joint crepitus & 16 & 5 \\
Painful, restricted movement & 16 & 1 \\
Not recorded & & \\
\hline GH, glenohumeral joint; AC, acromioclavicular joint. & \\
\hline
\end{tabular}

access the suprascapular notch and $0.5 \mathrm{ml}$ Omnipaque 300 (Nycomed, Sydney, Australia) was injected to exclude intravascular placement before injection of $40 \mathrm{mg}$ methylprednisolone acetate in and $3 \mathrm{ml}$ of $0.5 \%$ bupivacaine hydrochloride.

Baseline data, including clinical and radiological findings and disability, range of movement, and pain scores were gathered before the injection. Follow up data were gathered at weeks 1, 4, and 12 after the injection. The following data were gathered:

Table 3 The mean SPADI and pain scores with the standard deviation-landmark versus CT guided injection

\begin{tabular}{|c|c|c|c|c|c|c|c|c|}
\hline \multirow{2}{*}{$\begin{array}{l}\text { Outcome measurement } \\
\text { (max score) }\end{array}$} & \multicolumn{2}{|c|}{$\begin{array}{l}\text { Week } 0 \\
\text { Landmark }(n=40) \\
\text { CT guided }(n=37)\end{array}$} & \multicolumn{2}{|c|}{$\begin{array}{l}\text { Week } 1 \\
\text { Landmark }(n=39) \\
\text { CT guided }(n=34)\end{array}$} & \multicolumn{2}{|c|}{$\begin{array}{l}\text { Week } 4 \\
\text { Landmark }(n=37) \\
\text { CT guided }(n=35)\end{array}$} & \multicolumn{2}{|c|}{$\begin{array}{l}\text { Week } 12 \\
\text { Landmark }(n=36) \\
\text { CT guided }(n=33)\end{array}$} \\
\hline & Mean & SD & Mean & SD & Mean & SD & Mean & SD \\
\hline \multicolumn{9}{|l|}{ SPADI-total (100) } \\
\hline Landmark & 65.0 & 17.3 & 49.9 & 19.9 & 46.8 & 21.6 & 54.5 & 19.8 \\
\hline CT controlled & 68.9 & 13.9 & 55.0 & 22.7 & 55.5 & 21 & 60.6 & 20.9 \\
\hline \multicolumn{9}{|l|}{ SPADI-pain (100) } \\
\hline Landmark & 64.6 & 18.5 & 46.6 & 20.4 & 43.4 & 22.8 & 52 & 23 \\
\hline CT controlled & 68.9 & 15.4 & 51.9 & 23.8 & 52 & 24.6 & 58.2 & 22.5 \\
\hline \multicolumn{9}{|l|}{ SPADI-disability (100) } \\
\hline Landmark & 65.3 & 19.1 & 52.9 & 21.2 & 50.0 & 22.9 & 56.9 & 21.2 \\
\hline $\mathrm{CT}$ controlled & 67.1 & 17.7 & 58.1 & 23.9 & 58.7 & 21.3 & 62.6 & 21.2 \\
\hline \multicolumn{9}{|l|}{ Pain at rest (100) } \\
\hline Landmark & 31.2 & 22.1 & 20.8 & 19 & 18.0 & 17.1 & 25.4 & 18.0 \\
\hline $\mathrm{CT}$ controlled & 32.1 & 21.9 & 22.1 & 22.7 & 23.3 & 17.0 & 29.3 & 18.8 \\
\hline \multicolumn{9}{|l|}{ Pain at night (100) } \\
\hline Landmark & 48.6 & 23.4 & 29.0 & 20.5 & 26.2 & 18.3 & 35.8 & 24.0 \\
\hline CT controlled & 54.8 & 22.4 & 33.3 & 26 & 29.5 & 21.7 & 44.5 & 27.9 \\
\hline \multicolumn{9}{|l|}{ Pain on movement (100) } \\
\hline Landmark & 72 & 20.8 & 49.2 & 23.7 & 42.6 & 24.1 & 54.7 & 27.1 \\
\hline $\mathrm{CT}$ controlled & 76.5 & 17.8 & 47.8 & 23.4 & 48.4 & 24.5 & 57.1 & 23.0 \\
\hline
\end{tabular}




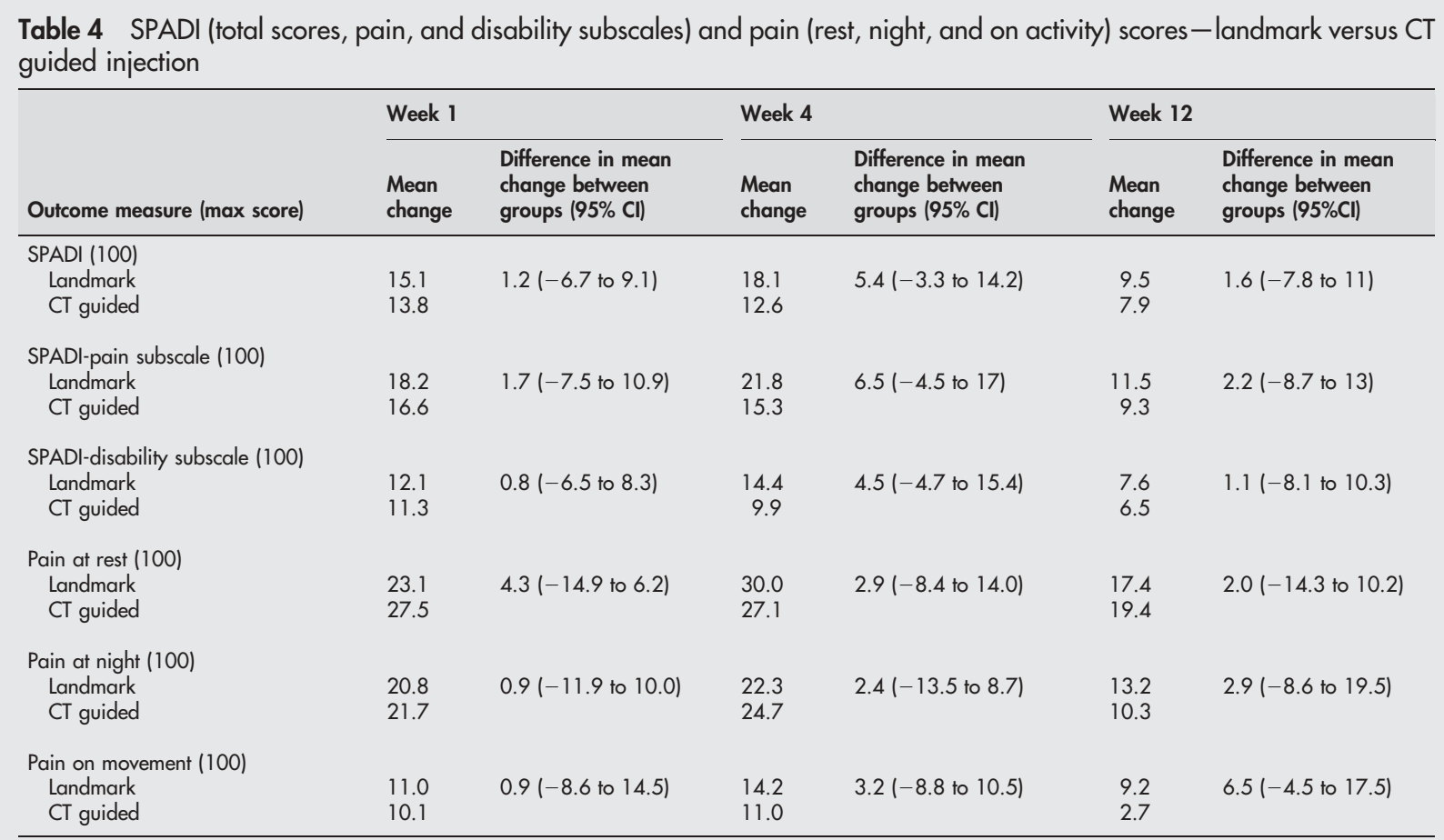

There are no significant differences between the two approaches at any time interval.

(a) baseline demographic and clinical information; $(b)$ baseline plain $x$ ray and ultrasound results; $(c)$ range of movement data at baseline, weeks 1, 4, and 12 (following the protocol developed by Green $e t \mathrm{al}^{8}$ ); (d) $100 \mathrm{~mm}$ pain visual analogue scale (VAS) scores at rest, at night, and with movement at baseline, weeks 1,4 , and $12^{9} ;(e)$ the shoulder pain and disability index (SPADI) at baseline and weeks 1, 4, and 12.

At the completion of the study, patients were asked about (a) their satisfaction with the degree of pain relief obtained; $(b)$ their satisfaction with the procedure; and (c) whether they would be willing to undertake the procedure again if indicated. All patient responses were recorded using $10 \mathrm{~cm}$ VAS.

\section{Statistical analysis}

Pain and disability relating to the shoulder as measured by the SPADI was considered as the major end point of the study. Pain measured on the VAS was considered a second major end point of the study. Range of movement was also considered to be a secondary end point. These outcomes were examined in the total group.

Power calculations were performed to determine the sample size at the study design stage. Assuming a power of $80 \%(\beta=0.2)$ and a type 1 error of 0.05 , a sample size of 38 subjects in each group had the power to detect a difference in a mean of 10 on the SPADI, assuming a common standard deviation of 15.3 using a two group $t$ test with a 0.05 two sided significance level. A mean difference of 10 on the SPADI is considered to be a clinically significant difference. ${ }^{10}$ This figure was chosen because it was felt that if there was to be a difference between the two approaches, it would need to be clinically significant. The analysis performed was an intention to treat analysis.

On 16 occasions a patient missed a follow up appointment. These data points were handled statistically by omitting the data point from analysis. Data were entered into the SPPS statistical package (version 10.0) $\chi^{2}$ Analyses were used for the difference between groups in the numbers of patients improving by more than 10 points on the SPADI.

\section{RESULTS}

Table 1 lists the demographic characteristics of the patients. The patients had received multiple treatments for shoulder pain before the study, with most having had pharmacological treatment (for example, non-steroidal anti-inflammatory drugs (NSAIDs) or simple analgesia) and/or intra-articular corticosteroid injections. Only five patients refused to participate in the study. They were not demographically different from the study group in any way. The principal reasons for refusal to participate were transport difficulties for follow up $(n=2)$, too old/frail $(n=2)$, concerned about the side effects $(\mathrm{n}=1)$. One other patient declined to

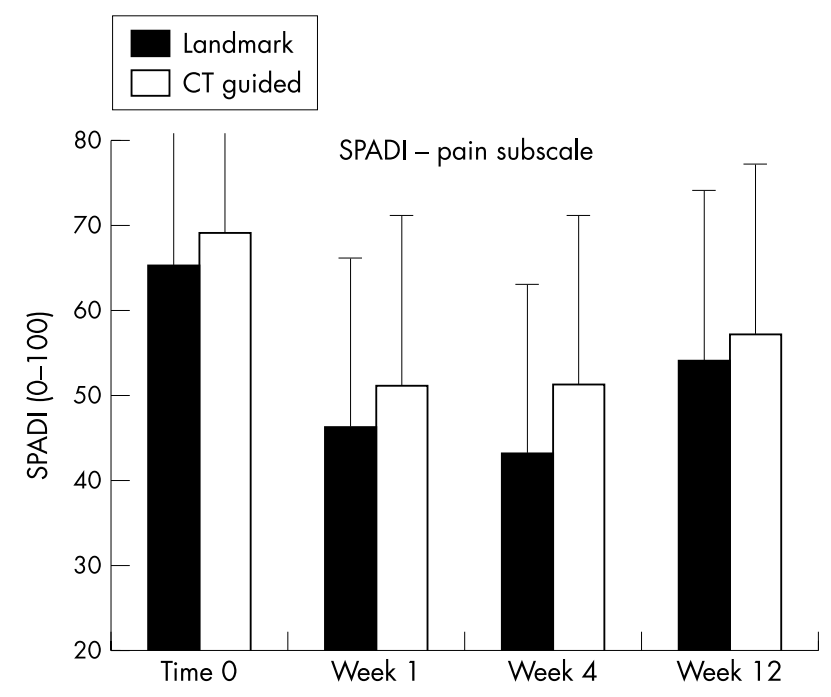

Figure 1 SPADI (pain subscale) mean results. Error bars are standard deviations. 


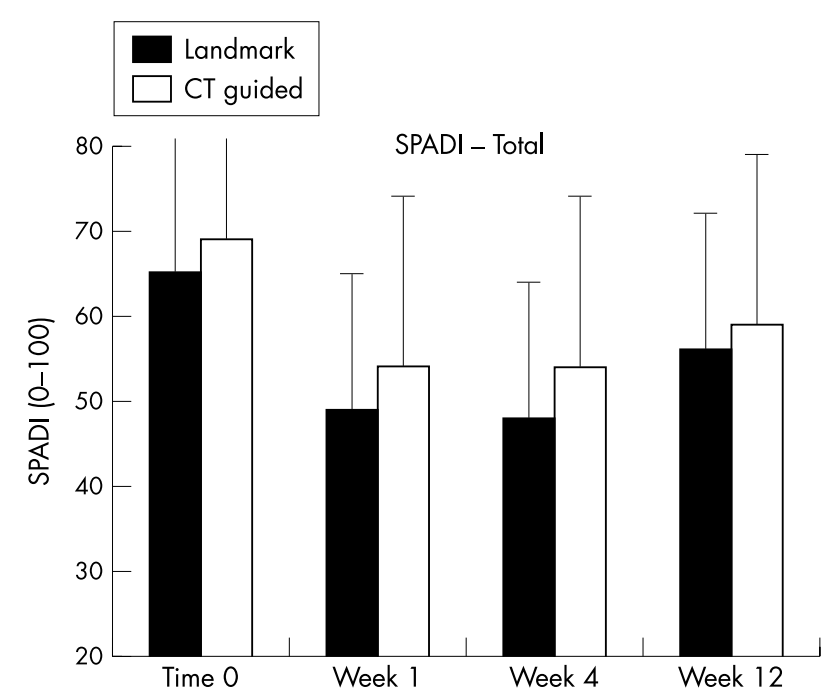

Figure 2 SPADI (total subscale) mean results. Error bars are standard deviations.

participate after baseline assessment and was therefore excluded from further analysis. The much smaller refusal rate in this study than in the previous study ${ }^{1}$ was thought to be due to the lack of a placebo arm. In all, 77 shoulders were included in the study. Table 2 summarises the radiological, clinical, and ultrasound findings of the participants.

Tables 3 and 4 summarise the data from the SPADI. Pain and disability subscales and the total scores are presented. Figures $1-6$ represent these outcomes graphically. Table 3 summarises the mean scores with $95 \%$ confidence intervals for the four time points. Table 4 shows the differences between the scores in the two groups over the three time periods. These data were analysed using the independent Student's $t$ test for the difference of the means. Table 5 summarises the range of movement data for abduction, flexion, external rotation, and hand behind back movements.

We then examined the percentage of shoulders that improved by more than 10 points on the SPADI scale in both groups at each time. At week 1, 60\% of shoulders in the landmark group improved by at least 10 points on the overall SPADI score compared with $44 \%$ in the CT guided group $(\mathrm{p}>0.10)$. At week 4 , the improvement rates were $70 \%$ and $50 \%$, respectively, $(p>0.10)$ and at week $1250 \%$ and $37 \%$ $(\mathrm{p}>0.10)$. That is, there were no significant differences in the proportions of people responding to the two approaches at any time interval.

\section{Adverse events}

Few adverse events were recorded in either group. One patient died before the 12 week follow up from ovarian cancer unrelated to the study. Another patient had shoulder surgery before completion of the 12 week period and was therefore excluded from the remainder of the study. The only side effects recorded from the injections were minor local reactions of bruising (two patients) and local pain (two patients). These complications settled quickly with local treatments.

Table 6 summarises the results of the answers to questions about patient satisfaction.

\section{DISCUSSION}

In some areas of medical practice there is a trend for clinicians to refer procedural interventions to radiologists in order to perform them under imaging control. For example, injections into glenohumeral joints, subacromial spaces,

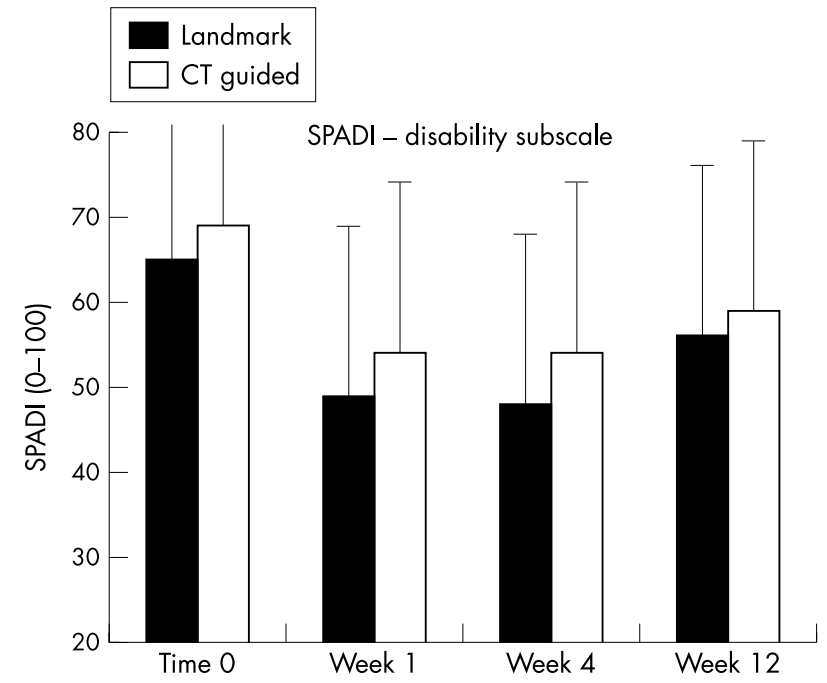

Figure 3 SPADI (disability) mean results. Error bars are standard deviations.

carpometacarpal joints, and plantar facial injections are often performed this way. This approach may be driven by the unproven impression that more precise needle placement afforded by imaging guidance is safer and results in better patient outcomes. However, the alternative approaches are rarely compared. It is important that comparative studies are undertaken as there is little doubt that the cost to the community is likely to be higher if a specialist radiologist undertakes the procedure than if they are carried out by a clinician in their rooms. However, relatively few studies directly compare imaging guided musculoskeletal procedures with indirect methods, using outcome measures based on patient centred measures. ${ }^{11}$

The costs of the two approaches can be compared. If costs are estimated based on the Australian Medicare schedule, the procedures performed by radiologists cost approximately \$4404.00 (€234.00, £165.00). This cost does not include the cost of the consultation required to refer the patient to the radiology service. This cost is approximately three times that of the procedure performed by a consultant rheumatologist in a clinic setting at an initial consultation (\$A140.00, €81.00, £57.00) or four times the cost if performed as part of a

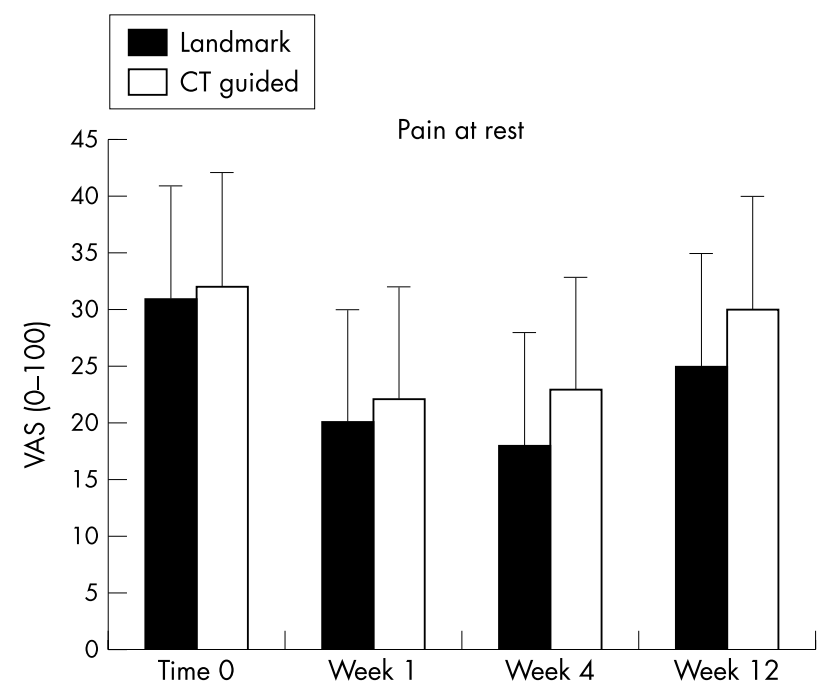

Figure 4 Pain at rest (mean results). Error bars are standard deviations. 


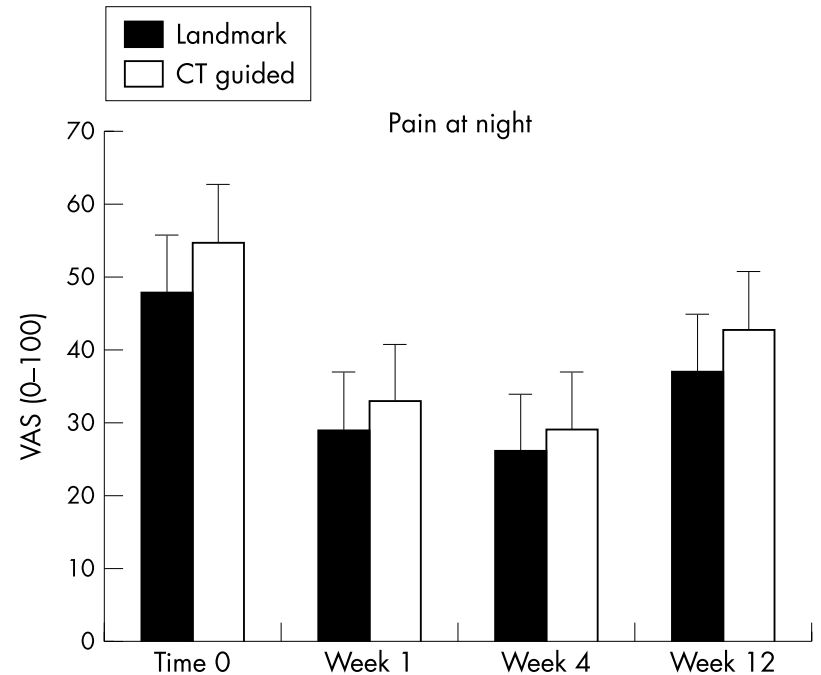

Figure 5 Pain at night (mean results). Error bars are standard deviations.

subsequent consultation (\$A100.00, $€ 58.00, £ 41.00$ ). If costs are estimated based on the use of staff time and consumables in a public hospital settling (rather than the Medicare schedule) the excess costs to the community for the radiological intervention compared with the intervention performed in the clinic is approximately \$A53.00 (€31.00, $£ 23.00$ ) for each procedure.

What are the potential advantages of a CT guided approach? The most obvious advantages are imaging guidance, allowing precise needle placement and delivery of smaller volumes of the therapeutic agents. It should be noted that although the same dose of methylprednisolone acetate

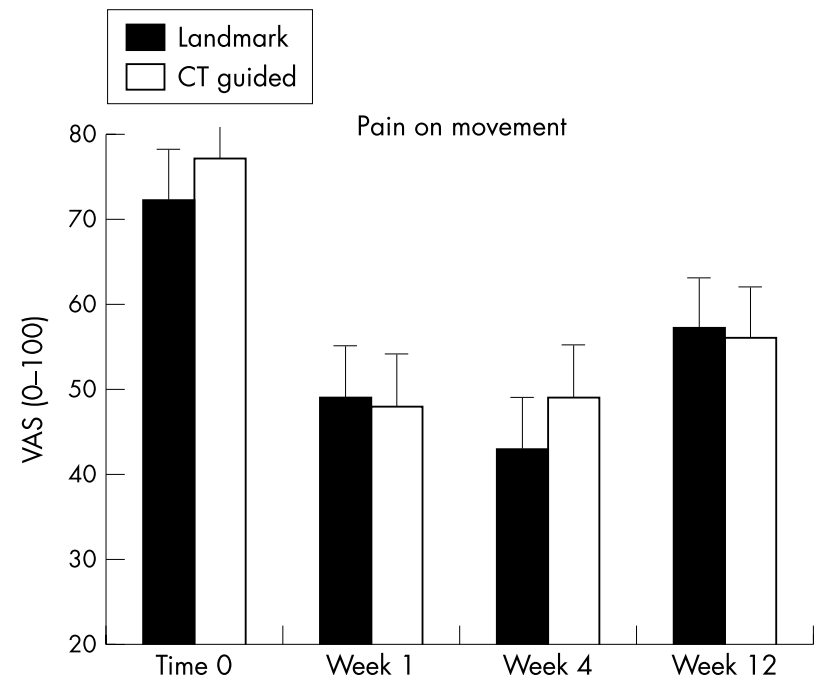

Figure 6 Pain on movement (mean results). Error bars are standard deviations.

was given in both groups, 10 and $3 \mathrm{ml}$ of $0.5 \%$ bupivacaine was injected using the indirect and CT techniques, respectively. Some may believe that more precise positioning of injected agents results in better clinical outcomes compared with an indirect approach, but this study has shown that there are no advantages for patient outcomes. A reduced risk of complications from the procedure is also a potential advantage of the radiologically guided procedure. Pneumothorax has been a reported complication from suprascapular nerve block in the past. ${ }^{12}$ In addition, there is a theoretical risk of nerve or vascular damage or inadvertent intravascular injection when a needle is introduced blindly into the

Table 5 The mean range of movement scores and standard deviation-landmark versus CT guided injection

\begin{tabular}{|c|c|c|c|c|c|c|c|c|}
\hline \multirow{2}{*}{$\begin{array}{l}\text { Outcome measurement } \\
\text { (max score-degrees*) }\end{array}$} & \multicolumn{2}{|c|}{$\begin{array}{l}\text { Week } 0 \\
\text { Landmark }(n=40) \\
\text { CT guided }(n=37)\end{array}$} & \multicolumn{2}{|c|}{$\begin{array}{l}\text { Week } 1 \\
\text { Landmark }(n=39) \\
\text { CT guided }(n=34)\end{array}$} & \multicolumn{2}{|c|}{$\begin{array}{l}\text { Week } 4 \\
\text { Landmark }(n=37) \\
\text { CT guided }(n=35)\end{array}$} & \multicolumn{2}{|c|}{$\begin{array}{l}\text { Week } 12 \\
\text { Landmark }(n=36) \\
\text { CT guided }(n=33)\end{array}$} \\
\hline & Mean & SD & Mean & SD & Mean & SD & Mean & SD \\
\hline \multicolumn{9}{|l|}{ Active abduction (180) } \\
\hline Landmark & 44 & 24.2 & 63 & 27.2 & 60 & 26.9 & 57 & 29.8 \\
\hline CT controlled & 35 & 18.7 & 56 & 29.2 & 59 & 28.0 & 51 & 31.6 \\
\hline \multicolumn{9}{|l|}{ Passive abduction (180) } \\
\hline Landmark & 54 & 26.1 & 74 & 30.0 & 69 & 28.5 & 66 & 31.3 \\
\hline CT controlled & 43 & 20.2 & 64 & 30.2 & 67 & 29.8 & 61 & 33.9 \\
\hline \multicolumn{9}{|l|}{ Active flexion (180) } \\
\hline Landmark & 58 & 31.9 & 75 & 32.8 & 78 & 37.8 & 75 & 37.3 \\
\hline CT controlled & 49 & 30 & 69 & 37.9 & 80 & 36.5 & 66 & 29.6 \\
\hline \multicolumn{9}{|l|}{ Passive flexion (180) } \\
\hline Landmark & 68 & 33.1 & 86 & 35.5 & 88 & 37.6 & 84 & 36.3 \\
\hline CT controlled & 57 & 29.5 & 73 & 37.9 & 89 & 37.6 & 76 & 31.1 \\
\hline \multicolumn{9}{|l|}{ Active ext rotation (45) } \\
\hline Landmark & 10 & 5.1 & 12 & 6.9 & 12 & 5.6 & 10 & 4.5 \\
\hline CT controlled & 9 & 4.2 & 10 & 5.9 & 12 & 5.3 & 12 & 5.0 \\
\hline \multicolumn{9}{|l|}{ Passive ext rotation (45) } \\
\hline Landmark & 13 & 6.0 & 16 & 9.3 & 15 & 6.8 & 14 & 5.4 \\
\hline CT controlled & 13 & 5.3 & 14 & 6.4 & 16 & 5.5 & 16 & 5.9 \\
\hline \multicolumn{9}{|l|}{ Hand behind back (20) } \\
\hline Landmark & 4 & 2.9 & 6 & 4.0 & 5 & 4.4 & 5 & 4.1 \\
\hline CT controlled & 4 & 3.6 & 6 & 4.2 & 7 & 4.6 & 6 & 4.8 \\
\hline
\end{tabular}

*All scores measured in degrees with the exception of hand behind back scores. This movement is measured on an interval scale where each progression of the thumb up a spinal vertebrae is one unit. 
Table 6 Patient satisfaction scores (Likert scale)landmark versus $\mathrm{CT}$ guided injection

\begin{tabular}{lll}
\hline & $\begin{array}{l}\text { Landmark } \\
\text { approach } \\
\text { (max 10) }\end{array}$ & $\begin{array}{l}\text { CT guided } \\
\text { approach } \\
\text { (max 10) }\end{array}$ \\
\hline Satisfaction with pain relief & 7.4 & 6.8 \\
Satisfaction with process & 8.1 & 7.3 \\
Willingness to have a repeat & 8.4 & 8.0 \\
\hline
\end{tabular}

suprascapular fossa. However, in this study and our previous study we have not reported any such events. Pneumothoraces have only been reported when a spinal needle was used, and we have demonstrated (albeit in a limited way) with previous imaging, that the shorter $38 \mathrm{~mm}$ needle, angled along the plane of the body of the scapula is unlikely to be long enough to be accidentally threaded through the suprascapular notch and into the lung. Our experience is similar to that of Dangoisse et al in this regard. ${ }^{7}$ The other potential advantage of imaging is to identify an unexpected cause for the shoulder pain, such as entrapment of the suprascapular nerve. ${ }^{13}$ However, these are rare events and in our series none of these incidental diagnoses were discovered. We do not believe that such incidental findings could justify the additional costs incurred by using the CT scanner to perform suprascapular nerve blocks.

The radiation exposure as a result of the CT scan was calculated at $1.5 \mathrm{mSv}$, which is about $75 \%$ of that received annually from natural background radiation. This dose results in a small stochastic risk from any one scan of this type. Obviously with repeated interventions this small risk would increase.

The patient satisfaction scores were of interest. Unfortunately, we did not have comparator scores from the previously performed placebo controlled study. ${ }^{1}$ Both methods of injection rated highly for satisfaction with pain relief. For satisfaction with the procedure, the indirect method scored slightly higher. This is probably because the procedure is quick and comfortable. The patient can sit in a chair, compared with lying prone for the CT guided approach. The prone position was a cause of some discomfort for a few people, especially those with cervical spondylosis. The patient satisfaction scores were recorded at the end of the 12 week period, and we suspect that had the questionnaire on comfort been completed immediately after the procedure then the discrepancy between the scores might have been greater.

The nature and methodology of this study is new. Despite the increasing popularity of clinicians referring patients for radiologically guided intervention, there have been few studies comparing the efficacy of these two approaches from the patient's perspective. Some studies do demonstrate superior needle positioning when guided by imaging, but most studies do not assess the impact this has on patient outcome. This study could be used as a model approach to examine this important question more thoroughly.

\section{ACKNOWLEDGEMENTS}

Dr Shanahan's work is supported by a grant from the National Health and Medical Research Council and the Arthritis Foundation of Australia.

The willing cooperation of the Medical Imaging Department at the Repatriation Hospital and Flinders Medical Centre under Professor Michael Sage is gratefully acknowledged. Statistical advice from Dr Michael Clark is also gratefully acknowledged.

\section{Authors' affiliations}

E M Shanahan, M D Smith, M Wetherall, M J Ahern, Rheumatology

Research Unit, Repatriation General Hospital, Daw Park, South

Australia, Australia 5041

C W Lott, J Slavotinek, Department of Medical Imaging, Flinders

Medical Centre and Repatriation General Hospital, Bedford Park South Australia, Australia 5041

O FitzGerald, St Vincent's University Hospital, Elm Park, Dublin 4, Ireland

\section{REFERENCES}

1 Shanahan EM, Ahern M, Smith M, Wetherall M, Bresnihan B, FitzGerald O. Suprascapular nerve block (using bupivacaine and methylprednisolone acetate) in chronic shoulder pain. Ann Rheum Dis 2003;62:400-6.

2 Schneider-Kolsky ME, Pike JW, Connell DA. CT-guided suprascapular nerve blocks-a novel technique. Abstracts of the Royal Australian and New Zealand College of Radiologists Annual Scientific Meeting Adelaide, Oct 2002:76-7.

3 Jones B, Jarvis P, Lewis JA, Ebbutt AF. Trials to assess equivalence: the importance of rigorous methods. BMJ 1996;313:36-9.

4 Emery P, Wedderburn L, Grahame R. Suprascapular nerve block for shoulder pain in rheumatoid arthritis. BMJ 1989;299:1079-80.

5 Brown DE, James DC, Roy S. Pain relief by suprascapular nerve block in glenohumeral arthritis. Scand J Rheumatol 1988;17:411-15.

6 Vecchio P, Adebajo A, Hazelman B. Suprascapular nerve block for persitent rotator cuff lesions. J Rheumatol 1993;20:453-5.

7 Dangoisse MJ, Wilson DJ, Glynn CJ. MRI and clinical study of an easy safe technique of suprascapular nerve blockade. Acta Anaesth Belg 1994;45:49-54.

8 Green S, Buchbinder R, Forbes A, Bellamy N. A standardized protocol for measurement of range of movement of the shoulder using the Plurimeter- $V$ inclinometer and assessment of its intrarater and interrater reliability. Arthritis Care Res 1998;11:143-51.

9 Huskisson EC. Measurement of pain. J Rheumatol 1982;9:768-9.

10 Williams JW Jr, Holleman DR, Simel DL. Measuring shoulder function with the shoulder pain and disability index. J Rheumatol 1995;22:727-32.

11 Eustace JA, Brophy DP, Gibney RP, Bresnihan B, FitzGerald O. Comparison of the accuracy of steroid placement with clinical outcome in patients with shoulder symptoms. Ann Rheum Dis 1997;56:59-63.

12 Moore DC. Block of the suprascapular nerve. In Thomas CC, ed. Regional nerve block, 4th ed. Springfield, 1979;9:300-3.

13 Vastamaki M, Goransson H. Suprascapular nerve entrapment. Clin Orthop Relat Res 1993;297:135-43. 